Eschilo in scena 


\section{DRAMA}

\section{Beiträge zum antiken Drama und seiner Rezeption}

Herausgegeben von

F. De Martino - J. A. López Férez -

G. Mastromarco - B. Seidensticker -

N. W. Slater - A. H. Sommerstein -

R. Stillers - P. Thiercy -

B. Zimmermann 


\title{
Beiheft 23
}

\author{
Andrea Blasina
}

\section{Eschilo in scena}

Dramma e spettacolo nell'Orestea

\author{
Verlag J. B. Metzler \\ Stuttgart · Weimar
}


Bibliografische Information Der Deutschen Bibliothek

Die Deutschen Bibliothek verzeichnet diese Publikation in der Deutschen Nationalbibliografie; detaillierte bibliografische Daten sind im Internet über <http:// dnb.ddb.de> abrufbar.

\author{
ISBN 978-3-476-45319-8 \\ ISBN 978-3-476-02936-2 (eBook) \\ DOI 10.1007/978-3-476-02936-2
}

Dieses Werk einschließlich aller seiner Teile ist urheberrechtlich geschützt. Jede Verwertung außerhalb der engen Grenzen des Urheberrechtsgesetzes ist ohne Zustimmung des Verlages unzulässig und strafbar. Das gilt insbesondere für Vervielfältigungen, Übersetzungen, Mikroverfilmungen und die Einspeicherung und Verarbeitung in elektronischen Systemen.

M \& P Schriftenreihe für Wissenschaft und Forschung

(C) 2003 Springer-Verlag GmbH Deutschland Ursprünglich erschienen bei J.B.Metzlersche Verlagsbuchhandlung und Carl Ernst Poeschel Verlag GmbH in Stuttgart 2003 
...l'anima che lo abitava era Cesare, che non presta ascolto alle ammonizioni dell'augure, e Giulietta, che ha in odio l'allodola, e Macbeth, che conversa nella landa con le streghe che insieme sono le parche. Nessuno fu tanti uomini come quell'uomo, che a somiglianza dell'egizio Proteo poté esaurire tutte le apparenze dell'essere. Talora, lasciò in qualche luogo della sua opera una confessione, certo che non sarebbe stata decifrata; Riccardo afferma che nella sua sola persona fa la parte di molti, e Jago dice con curiose parole: "Non sono quel che sono». L'identità fondamentale dell'esistere, il sognare e il rappresentare, gl'ispirò passi famosi. 